\title{
THE "DECOLONIAL TURN": WHAT DOES IT MEAN FOR ACADEMIC STAFF DEVELOPMENT?
}

\author{
Jo-Anne Vorster \\ Rhodes University \\ j.vorster@ru.ac.za \\ Lynn Quinn \\ Rhodes University \\ I.quinn@ru.ac.za
}

\section{ABSTRACT}

It has become increasingly evident that the discourse of transformation that has shaped the democratising of higher education institutions over the first two decades of the democratic dispensation in South Africa has now run its course. Over the past few years, and particularly during the tumultuous student protests of 2015 and 2016, students and some academics have been calling for the decolonisation of university structures and cultures, including curricula. Using concepts from Margaret Archer's social realism we consider the failure of the discourse of transformation to lead to real change and examine a constellation of new discourses related to the decolonisation of universities that have emerged in South Africa recently. Furthermore, we critique the discourses that have underpinned our own practices as academic developers over the past two decades and then explore the implications of what could be termed a "decolonial turn" for academic developers and by implication for the academics with whom they work.

Keywords: academic staff development; transformation; decolonial turn; social realism; curriculum

\section{INTRODUCTION}

After nearly two decades of working as academic staff developers and theorising our work, we now find ourselves confronting a major turn in our practice emerging from the crossroad at which South African higher education finds itself after recent tumultuous student protests. Underlying the student protests is an urgent call for the decolonisation of South African higher education. These calls aren't new. African intellectuals like Mbembe (2001), Alexander (2002) and Nyamnjoh (2012) amongst

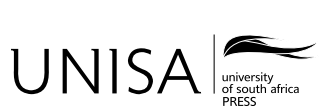

Education as Change

Volume 21 | Number 1 | 2017 | pp. 31-49

www.educationaschange.co.za

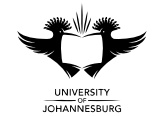

DOI: http://dx.doi.org/10.17159/1947-9417/2017/853 Print ISSN 1682-3206 | Online 1947-9417

(C) The Authors 2017 
many others have been critiquing the colonial nature of African universities for decades. The "decolonial turn" means different things for different people in different contexts (Maldonado-Torres 2011). It is beyond the scope of this paper for us to try and define such a complex concept. Instead in this paper we respond to what "the larger task of the very decolonisation of knowledge, power, and being, including institutions such as the university" (Maldonado-Torres 2011, 1) means for the practice of academic developers and for academics who may need to radically rethink their practices as teachers.

As academic staff developers we need to reconceptualise how we can work in productive ways in partnership with university teachers to decolonise institutional cultures and practices. In this paper we reflect critically on our past practices and consider how, in the face of a rapidly changing context in South African higher education, we can work with academics to respond to what could be called a "decolonial turn". We propose ways in which academic developers can work more effectively with academics who are confronting calls for major changes to curricula. This includes teaching and assessment methods that take into account the legitimate learning needs of all students.

We use theoretical lenses offered by social realism to gain insights into the contextual dynamics that shape our practices as we conceptualise how we respond to the current more radical calls for higher education transformation. Margaret Archer's (1995) concepts of culture, structure and agency are used to understand better the social phenomenon of academic staff development, and to evaluate critically our practices (including the values, theories and beliefs which underpin them) and structures which are produced and which in turn help to sustain those practices (Bhaskar 1989 cited in Sayer 1992, 39). Social realism is used to account for the interplay between personal and socio-cultural factors in explaining the variation of responses to the changing higher education context. We acknowledge that we are, perhaps somewhat ironically, using theoretical lenses which emanate from the global North and that any theories we use have limitations of which we need to be aware. As we allude to later in the paper, we are aware that it is time for us to seek new theoretical and analytical lenses and to develop our own theories appropriate for the global South.

1 Grosfoguel (2007) attributes the term "decolonial turn" to Puerto Rican Fanonian philosopher Nelson Maldonado-Torres. Grosfoguel also makes a distinction between colonialism and coloniality. The term coloniality refers to the "continuity of colonial forms of domination after the end of colonial administrations, produced by colonial cultures and structures in the modern/colonial capitalist/patriarchal world-system" (219). According to Maldonado-Torres (2007), coloniality can be understood as a system that defines the organisation and dissemination of epistemic, material, and aesthetic resources in ways that reproduce modernity's imperial project. In other words, coloniality represents the spaciality (expansionist control of lands), ontoepistemic racism (elimination and subjugation of difference) and geopolitics of knowledge production (epistemic violence) that are constitutive of modernity (Maldonado-Torres 2007) (de Oliveira Andreotti, Stein, Ahenakew and Hunt 2015, 23). 
We acknowledge that in writing this paper, we are venturing where angels fear to tread. Our academic and epistemological roots have not adequately prepared us for engagement with the concept of decolonisation and we fear that, as Tuck and Yang (2012) warn, we may be guilty of the superficial adoption of the language of decolonisation. It is necessary for us to guard against assuming that any of our pre-existing discourses and frameworks can easily be used as we explore what the "decolonial turn" could mean for academic development. Tuck and Yang argue that: "Decolonize (a verb) and decolonization (a noun) cannot easily be grafted onto pre-existing discourses/ frameworks, even if they are critical, even if they are anti-racist, even if they are justice frameworks" (Tuck and Yang 2012, 3).

We also need to acknowledge how difficult it is for us to articulate our ideas from within our current context and our current practices. Like Keet, we are "struggling to write from within the university space against dominant modes of disciplinary knowledge and against the social structure of the academy in Africa" $(2014,24)$. It is difficult for us to see things which are "obscured...located outside of our interpretive horizons" (ibid, 26). We do, however, believe that it is important that, as academic developers, we contribute to debates around how to respond to calls for institutional decolonisation.

Although the paper has been written in response to what has been happening in the South African context, the issues raised here will no doubt resonate with academic developers and academics in other parts of the African continent, the developing world generally, as well as in developed countries where student cohorts are becoming increasingly diverse (see, for example, Pett 2015).

\section{THEORETICAL FRAMEWORK: SOCIAL REALISM}

In much of our writing about staff development (Quinn 2012; Vorster and Quinn 2015) we have drawn on the work of critical realist, Roy Bhaskar (1979), and social realist, Margaret Archer (1995). ${ }^{2}$ In keeping with a critical realist understanding of a depth ontology, ${ }^{3}$ we have sought to go beyond the levels of the empirical (experiences) and the actual (events) to identify causal mechanisms at the level of the real. Important for

2 Critical realism is a philosophical approach or metatheory conceptualised by Roy Bhaskar. It combines a general philosophy of science with a philosophy of social science. Central to critical realism is the understanding that epistemology (people's knowledge of the world) is distinct from ontology (what is real). The major tenets of critical realism underpin social realism but are applied to the social world.

3 A "depth" ontology, as opposed to a "flat" ontology is an understanding of reality as multi-layered. According to Bhaskar, reality consists of three strata: 1) the empirical (people's experiences), 2) the actual (events), and 3) the real (structures and mechanisms which account for the first two strata). The objective of research is not only to examine experiences and events but also to try and uncover the deeper structures and mechanisms which account for why things are the way they are. 
this paper is Bhaskar's observation that the way things are at the level of events, and the way people experience events do not exclude "the possible", in other words, the way things could be. There are possibilities for change, which due to existing contextual constraints can only be partially realised, and often only in marginal spaces. However, if there is macro-level structural change, those changes could lead to broader systemic transformation. In this paper we point to ways in which the practice of academic developers and academics can challenge the status quo and contribute to transformative practice in higher education.

According to Archer (1995), society is made up of the "people" (agents) and the "parts" (culture and structure). In order to understand what occurs in any social context it is necessary to understand how the people respond to the constraints and enablements presented by the socio-cultural context. She argues strongly for what she calls "analytical dualism", that is, for first examining each of the entities (culture, structure and agency) separately before trying to understand the interplay between them: an "explanation of why things social are so and not otherwise depends upon an account of how the properties and powers of the 'people' causally intertwine with those of the 'parts"' (Archer 1995, 15).

Archer's concepts provide us with the means to theorise the complex interaction between the parts and people. They enable us to investigate the structural conditions of agency (for lecturers and academic developers) as well as the necessity of agency in the reproduction and transformation of social structures.

Culture or the cultural system, as defined by Archer (1995), is made up of ideas, ideologies, theories, beliefs and values which exist independently of whether people are aware of them, believe in them or agree with them. One way of uncovering cultural items is through identifying the discourses that are prevalent in a particular context. The ideas, beliefs, theories, values and so on that exist in a cultural system are manifested through the discourses used by particular people at particular times. From a realist perspective, discourses are real and have the potential to affect things in the world (Fairclough, Jessop and Sayer 2002). According to realist understandings, the objects of social science are relational. For example, in the context of higher education students and teachers are logically related to one another. So, what is of interest here are the logical relationships that exist between discourses or "cultural items" that have been identified in a specific context. These logical relations can either be consistent (complementary) with one another or they can be inconsistent (contradictory). For example, in the latter case a quality assurance discourse could be inconsistent with an academic freedom discourse. In this paper, we explore what we identify as the major contradictory cultural items that are prevalent in the broader context of higher education, as well as those that have underpinned our work as academic staff developers. Contradictions tend to create what Archer calls "situational logics", that is, "problem-ridden situations for actors which they must confront if and when they realise, or are made to acknowledge, that the proposition(s) they endorse are enmeshed in some inconsistency" (Archer 1996, xxii). 
We then theorise the effects of these contradictions on the practices of academics and academic developers in a context in which we are increasingly being made aware of the conflicting values and beliefs that underpin our practices. As Bhaskar says "to criticise a belief as false is ipso facto not only to criticise any action or practice informed or sustained by that belief, but also anything that necessitates it" $(1979,80)$.

Structure as used here refers to the differential distribution of material goods, the roles in institutions and society as well as "the other demographic markers that condition life chances: the workings of race, class, gender" (Case 2013, 31). Later we allude, for example, to the structural effects of colonialism, apartheid and postapartheid neoliberal approaches to higher education. Like cultural items, structures too can be consistent (complementary) with one another or they can be inconsistent (contradictory). We examine key structures and how they have impacted on the work of academic developers and academics.

The structural and cultural conditions of a specific context influence ways in which people can or can not exercise their agency. How people respond to structural and cultural constraints and enablements depends on their personal properties and powers. In Archer's words:

Human beings have the powers of critical reflection upon their social context and of creatively redesigning their social environment, its institutional or ideational configurations, or both... it is possible for human beings to become agentially effective...in evaluating their social context, creatively envisaging alternatives, and collaborating with others in bringing about transformation. (Archer 2000, 308)

Archer $(2000 ; 2007)$ contends that individuals discover particular "concerns" in relation to the society within which they live. These concerns become "projects" and from these projects they develop specific "practices". Throughout this process, they engage in reflexive deliberation (what Archer also calls "the internal conversation"). The academics with whom we work have invested much in the concerns and projects related to their disciplines and the teaching of their disciplines. How they exercise their agency in the face of the enablements and constraints they encounter in the socio-cultural context is thus intertwined with their professional identities and with the nature of the personal powers of critical reflection which they have developed. The challenge for academic developers is to understand the structural, cultural and agential mechanisms that may account for resistance to change and reluctance of academics to transform their practices.

In the following section we provide a brief analysis of the macro cultural and structural conditions of higher education in South Africa in order to develop a better understanding of the changed context which now confronts actors in higher education. Following Archer, we understand "context" as the "environment in which the ("macro') features of the system are either reproduced or transformed" $(1995,11)$. After that, we critique the values, theories and beliefs that underpin our staff development practices 
with a view to recognising how we, as academic developers, might need to exercise our agency to contribute to positive change in our contexts.

\section{EMERGING DISCOURSES IN THE SOUTH AFRICAN HIGHER EDUCATION CONTEXT ${ }^{4}$}

Following the advent of the democratic dispensation in 1994, the discourse of transformation in higher education has focused on the need for greater access (including epistemological access) for more black students, changing the demographic profile of staff, the creation of the National Qualifications Framework to facilitate the development of programmes of study in line with the so-called knowledge economy and to ensure equivalence and portability of credits and qualifications across institutions (RSA 1997). While student enrolments increased and there were improvements in staff demographics, the curricular changes envisaged with the introduction of the National Qualifications Framework did not materialise.

Historically little attention has been paid to the transformation of highly problematic institutional cultures until serious racial tension erupted at some historically white universities in 2015 and 2016. This had the effect of forcing awareness of the contradictory values and beliefs held by different groups in the higher education sector. It is therefore fair to say that in higher education the shifts towards real transformation have been limited. In fact, Case $(2015,3)$ argues that the continuation of the structural conditions inherited from the colonial and apartheid eras is "one of the under-recognised tragedies of the democratic settlement in South Africa".

Over the past two decades participation in higher education has increased moderately and now stands at approximately 19 per cent of the 18-24 year old population. Even though the majority of students in higher education is now black, this group accounts for only about 16 per cent of the 18-24 year cohort of black South Africans (Council on Higher Education 2016). Not only are the numbers of black and coloured students in higher education fewer than those for white and Indian students, but black students also fail and drop out of the system at disproportionately high levels. This structural contradiction is, to a large extent, due to the poor quality schooling still experienced by the economically disadvantaged.

Academic staff, particularly at historically white institutions, is still predominantly white. In addition, most academics across the racial spectrum have been schooled in and teach from a Western tradition and therefore continue to experience university spaces as generally congruent with their epistemological values, beliefs and practices. Because of this complementarity they have thus perhaps not felt the need to change the

4 Although we focus on South Africa, these discourses are emerging in many countries across the world. 
structural and cultural conditions in universities, including how curricula, pedagogy and assessment are structured.

Structurallymuch of the work of facilitating greater demographic and epistemological access of black students has happened in what is known in South Africa as extended degree programmes. In these programmes, students who fall short of meeting the entrance requirements of universities are taught in ways that bridge the articulation gap between school and university and that prepare them for successful engagement in the mainstream of university education. In historically white universities, extended degree programmes cater almost exclusively for black students. This has had a ghettoising effect and there is an expectation that students have to assimilate into the ways of being and doing of the university. It has also meant that the colonial influences on universities more broadly have not been questioned, that curricula and pedagogy have largely remained unchanged and that the necessary work of grappling with how to become the kinds of places where the majority of students can thrive and achieve success has not been done (Leibowitz and Bozalek 2015; Ndebele 1995). South African universities have been using a discourse of transformation while not engaging in significant structural and cultural changes beyond changing staff and student demographics.

The bleak picture of low access and success discussed above is indicative of an untenable contradiction that has led to students all over the country and some academics becoming impatient with and demanding that something be done about the slow transformation of universities. In addition to challenging high tuition fees, students have also challenged many cultural aspects of higher education by arguing for the sector to consider a more radical discourse of social and epistemic inclusion.

The protest movement initiated in 2015 has brought into stark relief the contradictions in the structural and ideational contexts of universities and their impact on the agency of students and academics; there can be little doubt that after the student protests "it can't be business as usual" for higher education any longer (Behari-Leak 2015). In an attempt to understand the changes that are necessary in universities, we have examined the discourses that have become dominant in the cultural system since the start of the recent student protests.

We have identified a constellation of four complementary and interconnected discourses related to the decolonial turn: 1) a strong discourse calling for the decolonisation of higher education, 2) a discourse of alienation, 3) a discourse of epistemological access explicitly understood as integrally linked to that of ontological access, and 4) a discourse of powerful knowledge.

A strong discourse calling for the decolonisation of higher education is now evident. There are indications that the discourse of transformation needs to be replaced by stronger discourses of change, such as the decolonising discourse, if the structural and cultural stasis in higher education is to be disrupted. One of the enduring effects of the long history of exclusion of black people from basic social and economic rights is that the achievement of epistemological and ontological access to the life and goods of the university remains an ongoing challenge. Throughout the student protests, black 
students have communicated their acute sense of alienation from formerly white higher education institutions (see for example, Behari-Leak 2015). The cultural milieu and structures of universities, including the buildings, symbols, ceremonies and rituals continue to privilege the traditions of the colonial Western universities from which the South African higher education system emerged (Lebakeng, Phalane and Dalindjebo 2006, 70). Many black students and staff feel that these institutional features, which are symbolic of the lack of real transformation in higher education, have the effect of rendering their presence on campuses invisible (Mbembe 2015). The second discourse, that is, the discourse of alienation, thus refers to students' sense of separation from the socio-cultural life of the university and in particular from the academic project. As noted earlier, these cultural and structural contradictions result in "problem-ridden" situations for many students and some staff.

Students have issued a challenge to academics to reconsider the appropriateness of disciplinary knowledge traditions and the values underpinning long established pedagogic practices. This challenge to the academic project stems to a certain extent from how students understand and experience higher knowledge. For most students, their initial encounter with specialised academic knowledge, including different forms and traditions of knowledge requires learning new ways of engaging with knowledge (Case 2015, 4). These new ways of reading, writing and thinking are alien and require significant effort and structured scaffolding to enable their acquisition. Appropriate pedagogy to induct students into these ways of learning is however not always present. In addition, if students feel alienated from their learning context it makes coming to terms with academic culture and discourse near impossible for many (McKenna 2004).

University curricula are not neutral as academics use their agency to select the content of their courses. The decolonial turn asks that academics consider "what knowledge and whose knowledge is important for institutions located on the southern tip of Africa" (Case 2015, 4 emphasis in the original; Mignolo 2009). The bulk of the canon in most disciplines taught at South African universities emanates from the global North. Knowledge that has emerged from (South) Africa and elsewhere in the global South, has generally not been included in the curriculum, even in spaces where it would, quite obviously, be relevant. The nearly universal adoption of the Western knowledge tradition creates, for many students, a sense of "a hierarchy of superior and inferior knowledge and, thus, of superior and inferior people" (Grosfoguel 2007, 214).

Wally Morrow's concept of "epistemological access" has been part of the transformation discourse for a number of decades. However, when it is used uncritically, as has largely been the case in South Africa, it has contributed to what Fricker (2007) and others call "epistemic othering" and "epistemic injustice". There has been insufficient critique of what "epistemologies" students should have access to. As Keet says: "Only if we view the 'decolonisation of knowledge' as the collective processes by which disciplinary practices are successful in working against the inscribed epistemic injustices of all knowledge formations can we claim for ourselves a commitment towards epistemic justice" (Keet 2014, 35). 
Even though some black academics have also articulated their own discomfort with and alienation from contradictory university structures and cultures, it is probably fair to say that the majority of white academics have not experienced the same kinds of contradictions. They now need to confront the reality of having long mis-recognised a large proportion of our students and their needs (Bozalek and Boughey 2012). Case $(2015,4)$ argues that postcolonial South Africa has created

two different classes of students in our universities - those who have learnt to enjoy the rights of being a citizen, and those whose subjected identities result from a family upbringing in the subjected margins of our society, those who have learnt through experience that rights are the domain of privileged others.

It is particularly for the benefit of the latter group (which constitutes the majority of black students) that we need to consider what the postcolonial university could look like in South Africa and elsewhere.

In examining what it might mean to decolonise the university it is important to rethink how we understand the purposes of the university and what it means for curricula, teaching and learning. Badat $(2015,2)$ argues that this requires serious engagement with "research, scholarship, learning and teaching, curriculum, pedagogy and a host of other issues and their meanings in a society that must overcome its apartheid past and ensure human rights and justice for all".

For black students, curricula and pedagogic processes are often not aligned with who they are as people and it is not possible to divorce themselves - their being - from what is taught and how it is taught. What they are arguing for is greater recognition that teaching and learning is not only an epistemological project, but, in essence, also an ontological one. In examining the so-called "ontological turn" in higher education Dall'Alba and Barnacle (2007) and Barnett (2009) argue that epistemology shapes ontology. Knowledge is learned in order for a student to be(come) a particular kind of person in the world. Dall'Alba and Barnacle suggest, following Barnett and Coate (2005), that in order to achieve the ontological turn it is necessary to integrate knowing, acting and being. It is crucial in our context that the third discourse we identified, the discourse of epistemological access, must be critiqued and explicitly understood as integrally linked to that of ontological access.

As scholars who work from a social realist orientation to knowledge, we are not advocating that canonical knowledge be discarded simply because it is the knowledge of the powerful. We recognise the power of this knowledge. A social realist perspective is not uncritical of the idea that powerful knowledge automatically confers power on "a particular type of knower" (Moore 2009, 6), but instead argues that it is important to open up access to powerful knowledge to all people - what Wheelahan (2007) calls "distributive justice". It is therefore important to reconsider and broaden what we regard as powerful knowledge and therefore what needs to be included in curricula. It is thus important to interrogate the discourse of powerful knowledge (Wheelahan 2007; Young 2008) and to ask questions about what it is that particular knowledges are powerful 
for or what imbues them with power. Inasmuch as we understand that the power of knowledge lies in its explanatory power, it is also necessary to acknowledge that this power will not be recognised as long as many students continue to be alienated from this knowledge. It is therefore imperative that we get to know a broader range of bodies of disciplinary scholarship, including epistemologies. We concur with Zipin, Fataar and Brennan (2015) that it is important to take account of both the epistemological (cognitive) purposes of education as well as the axiological (ethical) purposes. This is particularly the case in post-apartheid South Africa where issues of social justice should be paramount.

Enabling both epistemological and ontological access to a range of knowledges means paying attention to curricular choices and in particular to pedagogic processes. Higher learning requires a process of distanciation, through theory, so that the object of knowledge is better understood (Slonimsky and Shalem 2004). However, good pedagogy means that there should be, at least when ideas and theories are first taught, constant movement between what is known and the new knowledge to which students are introduced. It is therefore pedagogically sound, where appropriate, to make explicit the links between knowledge and its contexts of origin and application.

In summary, from our analysis of the macro context above we have chosen to highlight four complementary discourses which have emerged in recent times that are inconsistent with earlier dominant discourses. We think academic staff developers need to consider the implications of these discourses for their work. They are: a strong decolonisation discourse to replace the transformation discourse; a discourse of alienation felt by black students and staff; a discourse that recognises the strong link between epistemology and ontology; and finally a discourse that questions traditional conceptions of "powerful" knowledge.

In the following section we examine the discourses that have informed our staff development work for the last two decades and critically examine whether these discourses are complementary or contradictory with the emerging macro discourses.

\section{ACADEMIC STAFF DEVELOPMENT}

Academic developers potentially have a crucial role to play in preparing academics for their teaching role in challenging contexts globally. We agree with Clegg (2009, 54) that as "a project it [academic development] is oriented towards change (Land 2004) to transformation, rather than stasis (Archer 1995)". This means that we have to be especially aware of the contexts in which we operate so that the work we do with lecturers leads to teaching and learning that foregrounds both the academic project and the real needs of students.

Historically, the project of academic development in South Africa has been to work towards the achievement of social justice (Boughey 2007; Clegg 2009; Quinn 2012) by contributing to the development of the kind of teaching and learning practices that would mean academic success for the majority of students. Up to now, this has meant 
ensuring that students understand the notion of disciplinary discourses, the research paradigms and methodologies of the disciplines, how to read discipline-based texts and how to write in ways that are congruent with knowledge-making in the disciplines. The role of academic developers has been to devise and share with lecturers ways in which they can scaffold the enculturation of students into the ways of being in their disciplines and the university.

We have worked in a variety of ways with academics both from our own institution as well as from a range of other types of South African higher education institutions. ${ }^{5}$ Predominantly, the work has been done through offering a postgraduate diploma in higher education which is similar to postgraduate certificates offered in the UK and elsewhere. The diploma is offered part time over two years and includes modules on teaching and learning, curriculum, assessment of student learning and evaluation of teaching and courses.

In previous research on the knowledge and pedagogy of the diploma, we identified the discourses (or "cultural items" in Archer's terms) that underpin the design and teaching of the course (Vorster and Quinn 2012a; 2012b). First, the purpose of the course is to offer lecturers the theoretical and practical tools that will enable them to support epistemological access (Morrow 1994) for a diverse student body. We argue that this is the main axiological principle informing the course; that lecturers have a moral responsibility to work towards not just formal access to university, but also academic success for the majority of students. The second underpinning discourse, based on our belief that academics' identities are very strongly informed by their disciplines (Becher and Trowler 2001; Henkel 2000), is that of respecting the disciplinary differences, expertise and identities of the academics with whom we work. In common with many professional development courses, the third discourse which informs our work is that of the critically reflexive practitioner (Light and Cox 2000; Schön 1983), which entails going beyond only being concerned about individual actors to also being concerned about wider issues related to disciplines and societies. The fourth discourse entails a belief that teachers' curricular and pedagogic practices need to be underpinned by "strong" theories and not based on common-sense, skills-based understandings of teaching and learning. We thus see our role as academic staff developers as encouraging critical engagement with the theory and practice of higher education.

If we really want to respond to the "turn" we describe above, we have to ask ourselves: Have these discourses been sufficient and are they robust enough for the task at hand? Like Clegg, we too wonder if "academic development can be remade in ways

5 Our home institution is an historically white institution that has been particularly affected by the historical legacies of colonialism and apartheid. However, the many other historically black institutions we have worked in have also been affected by these historical legacies, although in different ways. We have had to rethink our practices in both of these contexts. 
that pay attention to other more critical discourses" (Clegg 2009, 63), such as the four discourses in the macro context identified above.

In rethinking these discourse now, we have, as mentioned earlier, become aware of the limitations of using the concept of "epistemological access" uncritically as it can be applied in conservative ways which result in accommodating the "other" in existing colonial cultures and structures rather than questioning them. We need to ask critical questions about access to what, for whom and how (Mignolo 2009). What disciplinary knowledge is selected and what pedagogies are most appropriate should be considered in the light of who the students are. Asking critical questions about knowledge are "necessary steps for imagining and building democratic, just, and non-imperial/colonial societies" (Mignolo 2009, 2).

On reflection, although we have encouraged lecturers to be critical of their practices, to take into account issues of transformation such as equity, social justice and inclusion, these ideas were largely framed as being related to pedagogical issues rather than to decolonising the university, knowledge and curricula. The newer, stronger discourses are not necessarily incompatible with the discourses we have been using, although it will require a lot of work for us to understand exactly what the calls for decolonisation mean in the university and in the different disciplines.

At this point we have only just begun to recognise the magnitude of the task of ourselves making sense of what it might mean to understand "epistemic justice as central to the disruption of the discipline" (Keet 2014, 23). We ourselves are, as Keet says, "struggling to write from within the disciplinary knowledge and against the social structure of the academy in Africa" (ibid, 24). In terms of our practice as academic developers this leaves us feeling between a rock and a hard place: if we ourselves are struggling to see beyond the "hegemonic eye" (Santos 2007) of our own knowledge fields, the question is: how do we encourage the lecturers with whom we work to do this?

As de Oliveira Andreotti et al. (2015) explain, understanding what decolonisation means is not easy; the multiple meanings and motives for championing it are varied, contested, and at times, contradictory. In addition to this complexity, the decolonising discourse creates a constraining contradiction for lecturers whose identities are strongly tied to the traditional canon of their disciplines. We have not, in our teaching, required lecturers to interrogate at a much deeper level their disciplinary concerns and projects in relation to the newer discourses in the socio-cultural context. As academic developers, this means we will need to create spaces for lecturers to explore "the complexities, tensions and paradoxes of decolonising work without an immediate need for resolution, coherence and prescriptive action" (ibid, 22). In fact our challenge will be to work with academics "to face the incoherence (and frustration) of the juxtaposed, incommensurable contexts they will have to inhabit, navigate and negotiate in" (ibid, 30).

Although few academics would disagree that epistemological access is the aim of higher education, some experience uncomfortable contradictions when challenged to consider issues of which knowledges to choose when designing curricula and how the 
choice of knowledges can impact on students. For academics whose work is underpinned by more conservative, traditional discourses such as the centrality of the traditional canon, calls to decolonise their curricula might challenge their deeply held beliefs and their strong disciplinary identities (Henkel 2000). As mentioned earlier, contradictory ideas create situational logics for actors. In this context, it may be a case of "[t]hose whose interests are served by the new item have to stand up and fight for it; those whose traditional sway is threatened by its actualisation have to weigh in and fight against it" (Archer 1996, 204). This presents a difficult context for academic developers to work in.

Understanding this effect of the "turn" on some academics requires of us, without losing our respect for disciplinary identities, knowledge and expertise, to engage in courageous conversations and to ask some searching questions about what epistemological access really means and what knowledges they choose to select for their curricula. We are not advocating continued unquestioning teaching of the canon but neither are we necessarily arguing for discarding it. Academics should be encouraged to engage with critiques of their disciplines and with the dangers of drawing only from the traditional canon, which consists mainly of the knowledge of the powerful; they need to investigate knowledges that hitherto have been ignored: "hegemonic tradition has not only become hegemonic. It also actively represses anything that actually is articulated, thought and envisioned from outside of these frames" (Mbembe 2015, 10). The dilemma is that we, as academic developers, do not have the power to change these dominant disciplinary structures. However, we do need to ask more challenging and critical questions which may facilitate "the decolonisation of knowledge with concomitant possibilities for innovative knowledge practices that view epistemic justice as central to the disruption of the disciplines" (Keet 2014, 23). So in our conversations with lecturers we could, for example, ask them to consider the following:

- Why do you only draw knowledge from Europe, the USA, the Western world or the global North?

- Can you use examples of how this knowledge is used in Africa/the global South?

- How is this knowledge linked to the histories of different students in your class? How does it validate their lives?

- Have you critically examined your curricula, pedagogy and assessment methods for practices which some students may find alienating?

As the last two questions imply, we need to encourage lecturers to see the links between epistemology and ontology, to consider the reality of all the students in their classes. We must, however, not be blind to the difficulties of doing this as this discourse will clash with discourses around objectivity and distanciation traditionally associated with higher education learning. In our courses we need to demonstrate ways in which academics can design curricula, teach and assess in ways in which students are heard, listened to, understood and can thrive; ways in which we can create the spaces for students regardless of background or history, to, in Mbembe's words, say: "This is my home. I 
am not an outsider here. I do not have to beg or to apologise to be here. I belong here" $(2015,5)$.

In common with many academic developers globally we have worked hard to encourage academics to be critically reflexive practitioners (Quinn and Vorster 2004) and to question traditional pedagogies and ways of assessing. We have had a measure of success in terms of promoting ideas related to what we consider to be "good" teaching, such as getting to know who your students are, catering for the legitimate learning needs of the students in front of you and not the mythically well-prepared students you would like, engaging with knowledge students bring into the course, using pedagogies that give students opportunities to engage actively in learning and to link their existing knowledge to new knowledge, inducting them into the literacies and ways of "being" of disciplines, using reliable, valid and fair methods to assess their students, and so on. Although we have had success in promoting a certain level of critical reflection, we would argue that it is now time for academic developers to push the boundaries and challenge academics to engage with the more radical critical discourses that are emerging.

In Archer's terms (2000), we need to create spaces for academics to build their personal properties and powers, to become what she calls "meta-reflexives"; that is, people who can consider their concerns, projects and practices in relation to the wider social concerns and thus be prepared to have entrenched identities, values and beliefs challenged. Our work thus needs to be informed by stronger discourses that ask more critical questions related to the influence of colonialism on higher education. Questions about what is taught and how it is taught, such as the ones suggested above, as well as questions such as: Who teaches? What kind of person is the discipline trying to shape? Is it a way of being that values who students are? Is it a way which acknowledges different knowledges and ways of being? Asking these questions of ourselves and the lecturers with whom we work is a challenging space for academic developers; a space where angels fear to tread but which will need to be trodden more explicitly.

In confronting the "turn" we should also shift the gaze of the critically reflexive practitioner to our own beliefs and practices. There are two areas in particular which we believe need to be interrogated: First, are the strong theories/knowledge we have been working with in the past the "right" ones for now? In our bid to be "scholarly" and draw from "strong" theories, we have ourselves predominantly drawn on theories and ideas about teaching and learning from the UK, USA and Australasia. It is time for us to broaden the theoretical stock pot from which we draw to include perspectives from the global South. In addition, as a community of academic developers we should be undertaking more research that results in theories and concepts which emerge from our own contexts. Academic development colleagues such Kathy Luckett (2016) have already begun this work, particularly in relation to humanities curricula in a postcolonial context.

Second, are we working in ways which take full cognisance of the realities of the lecturers with whom we are working and the contexts within which they work? 
Understanding what it feels like to be the only (or one of a few) black lecturers in a department and in an institution that is clearly more comfortable for white lecturers is important if we wish to have meaningful interactions. Really getting to know the lecturers who attend our courses will help us to create safe-yet-challenging spaces for them to explore their development as teachers in higher education.

Academic developers need to courageously question the values and beliefs that underpin their work so that they are able to accompany lecturers on journeys such as the one described by an academic below:

I am also in the process of relocating myself as an academic into uncertain new epistemic terrain. For me this has meant questioning my assumptions, making my biases visible, and seeking new voices and ways of thinking that have Africans as subjects, not objects of pedagogy. The process...requires a shift of paradigms that are the foundations not only of thought but also of action. (Knowles 2015, 3)

Academic developers should take on stronger agential roles so that they can have a voice in as many university structures as possible. These are spaces in which to ask uncomfortable questions related to institutional culture and ethos, and questions challenging resistance to change. We need to acknowledge to ourselves and convince academics with whom we work that education is never neutral; it is always underpinned by a political agenda and currently we are urgently needing to consider the implications of a shifting political agenda.

\section{CONCLUSION}

The recent protests have put the spotlight on South African society's inability to transcend the legacy of its colonial and apartheid past and to create the conditions for young people to achieve their goals of making a better life for themselves and their families (Case 2015, 1). With the emerging decolonial turn higher education has the opportunity to conceptualise an educational response to the static structural and cultural realities in universities. It is now possible to create conditions conducive to engaging with students who have felt alienated from universities by taking seriously the pedagogic rights of individual enhancement, the right to be included and the right to participate (Bernstein 1996).

In this paper, using a social realist lens, we examined our context and our experiences as academic staff developers to conceptualise what the calls for decolonisation may mean for the practice of academic developers and by implication for the academics with whom we work. Although this analysis is context specific, we argue that higher education in many countries is experiencing similar challenges to traditional cultural and structural conditions and academic development work in these contexts may need to wrestle with how to contribute to reshaping university teaching and learning.

In a context of decolonisation where calls are made for institutional cultures and practices to be better aligned with the epistemological and ontological needs of the 
majority of students, as academic developers we have to rethink the frameworks we draw from for professional development. To respond to the changing context our work now needs to be informed by much stronger transformation discourses. Furthermore, we should work with lecturers to understand what decolonisation may mean in their specific disciplinary and institutional contexts by asking much more challenging questions of lecturers related to curriculum decisions and the effects of those decisions on all their students. At the same time though, we also need to support them when they feel their identities are under threat. Finally, we suggest that as academic developers we should reflect on our curriculum decisions, particularly those related to the knowledge we use in our teaching. We too, need to pay particular attention to the lived realities of all the academics with whom we work.

Academic developers have a role to play in making possible institutional contexts in which both academics and students are able to flourish and contribute to the academic project in ways that are congruent with being part of a university at the southern tip of Africa as part of a global world.

\section{REFERENCES}

Alexander, N. 2002. An Ordinary Country: Issues in the Transition from Apartheid to Democracy in South Africa. Scottsville: University of Natal Press.

Archer, M. S. 1995. Realist Social Theory: The Morphogenetic Approach. Cambridge: Cambridge University Press.

Archer, M. S. 1996. Culture and Agency. The Place of Culture in Social Theory. Cambridge: Cambridge University Press.

Archer, M. S. 2000. Being Human. The Problem of Agency. Cambridge: Cambridge University Press.

Archer, M. S. 2007. Making Our Way through the World: Human Reflexivity and Social Mobility. Cambridge: Cambridge University Press.

Badat, S. 2015. "Putting an End to Causes of Pain.” Graduation Speech, Rhodes University, April.

Barnett, R. 2009. "Knowing and Becoming in the Higher Education Curriculum." Studies in Higher Education 34 (4): 429-40.

Barnett, R., and K. Coate. 2005. Engaging the Curriculum in Higher Education. Maidenhead: Society for Research into Higher Education and Open University Press.

Becher, T., and P. Trowler. 2001. Academic Tribes and Territories: Intellectual Enquiry and the Cultures of Disciplines. $2^{\text {nd }}$ ed. Buckingham: Society for Research into Higher Education and Open University Press.

Behari-Leak, K. 2015. “After Protests, It Can't Be Business as Usual at South Africa's Universities.” The Conversation, November 18. https://theconversation.com/after-protests-it-cant-be-business-as-usualat-south-africas-universities-50548 (accessed November 22, 2015). 
Bernstein, B. 1996. Pedagogy, Symbolic Control and Identity. Oxford: Rowman and Littlefield.

Bhaskar, R. 1979. The Possibility of Naturalism. A Philosophical Critique of the Contemporary Human Sciences. Brighton: Harvester.

Boughey, C. 2007. "Educational Development in South Africa: From Social Reproduction to Capitalist Expansion?" Higher Education Policy 20: 5-18.

Bozalek, V., and C. Boughey. 2012. "(Mis)Framing Higher Education in South Africa." Social Policy and Administration 46 (6): 688-703.

Case, J. 2013. Researching Student Learning in Higher Education: A Social Realist Approach. London: Routledge.

Case, J. 2015. "Reimagining the Curriculum in a Postcolonial Space: Engaging the Public Good Purposes of Higher Education in South Africa." Keynote address. HELTASA, North West University, Potchefstroom, 17-20 November.

Council on Higher Education (CHE). 2016. South African Higher Education Reviewed. Two Decades of Democracy. Pretoria: Council on Higher Education.

Clegg, S. 2009. "Histories and Institutional Change: Understanding Academic Development Practices in the Global 'North' and 'South'." International Studies in Sociology of Education 19 (1): 53-65. DOI: $10.1080 / 09620210903057715$

Dall'Alba, G., and R. Barnacle. 2007. "An Ontological Turn for Higher Education.” Studies in Higher Education 32 (6): 679-91.

De Oliveira Andreotti, V., S. Stein, C. Ahenakew, and D. Hunt. 2015. "Mapping Interpretations of Decolonization in the Context of Higher Education." Decolonization: Indigeneity, Education and Society 4 (1): 21-40.

Fairclough, N., B. Jessop, and A. Sayer. 2002. "Critical Realism and Semiosis.” Journal of Critical Realism (Incorporating Alethia) 5 (1): 2-10.

Fricker, M. 2007. Epistemic Injustice. Power and the Ethics of Knowing. New York: Oxford University Press.

Grosfoguel, R. 2007. “The Epistemic Decolonial Turn: Beyond Political-Economy Paradigms.” Cultural Studies 21 (2-3): 211-23.

Keet, A. 2014. "Epistemic 'Othering' and the Decolonisation of Knowledge.” Africa Insight 44 (1): 23 -37.

Henkel, M. 2000. Academic Identities and Policy Change in Higher Education. London: Jessica Kingsley Publishers.

Knowles, C. 2015. Points to Ponder. Strengthening Postgraduate Supervision. Centre for Higher Education Research, Teaching and Learning. Grahamstown: Rhodes University. 
Lebakeng, J. T., M. M. Phalane, and N. Dalindjebo. 2006. "Epistemicide, Institutional Cultures and the Imperative for the Africanisation of Universities in South Africa." Alternation 13 (1): 70-87.

Leibowitz, B., and V. Bozalek. 2015. "Foundation Provision - A Social Justice Perspective." South African Journal of Higher Education 29 (1): 8-25.

Light, G., and R. Cox. 2000. Learning and Teaching in Higher Education: The Reflective Professional. London: Paul Chapman.

Luckett, K. 2016. "Curriculum Contestation in a Post-Colonial Context: A View from the South.” Teaching in Higher Education 21 (4): 415-28.

Maldonado-Torres, N. 2007. “On the Coloniality of Being.” Cultural Studies 21 (2-3): 240-70.

Maldonado-Torres, N. 2011. "Thinking through the Decolonial Turn: Post-Continental Interventions in Theory, Philosophy, and Critique - An Introduction.” Transmodernity: Journal of Peripheral Cultural Production of the Luso-Hispanic World 1 (2): 1-14.

Mbembe, A. 2001. On the Postcolony. London: University of California Press.

Mbembe, A. 2015. "Decolonizing Knowledge and the Question of the Archive." Public lecture, Johannesburg, Wits Institute for Social and Economic Research (WISER).

McKenna, S. 2004. "The Intersection between Academic Literacies and Student Identities." South African Journal of Higher Education 18 (3): 269-80.

Mignolo, W. D. 2009. "Epistemic Disobedience, Independent Thought and De-Colonial Freedom.” Theory, Culture and Society 26 (7-8): 1-23.

Moore, R. 2009. Towards the Sociology of Truth. London: Continuum.

Morrow, W. 1994. "Entitlement and Achievement in Education." Studies in Philosophy and Education 13 (1): 33-7.

Ndebele, N. 1995. “Maintaining Domination through Language.” Academic Development 1 (1): 3-5.

Nyamnjoh, F. 2012. "Potted Plots in Greenhouses: A Critical Reflection on the Resilience of Colonial Education in Africa." Journal of Asian and African Studies 47 (2): 129-54.

Pett, S. 2015. "It's Time to Take the Curriculum Back from Dead White Men." The Conversation, May 8. https://theconversation.com/its-time-to-take-the-curriculum-back-from-dead-white-men-40268 (accessed November 22, 2015).

Quinn, L. 2012. “Introduction.” In Re-Imagining Academic Staff Development: Spaces for Disruption, edited by L. Quinn, 1-14. Stellenbosch: Sun Media.

Quinn, L., and J. Vorster. 2004. "Transforming Teachers' Conceptions of Teaching and Learning in a Postgraduate Certificate in Higher Education and Training Course." South African Journal of Higher Education 18 (1): 364-81. 
Santos, B. 2007. "Beyond Abyssal Thinking: From Global Lines to Ecologies of Knowledges." Eurozine, June 29. http://www.eurozine.com/articles/2007-06-29-santos-en.html (accessed November 22, 2015).

Sayer, A. 1992. Method in Social Science. A Realist Approach. $2^{\text {nd }}$ ed. London: Routledge.

Schön, D. 1983. The Reflective Practitioner: How Professionals Think in Action. London: Temple Smith.

Slonimsky, L., and Y. Shalem. 2004. "Pedagogic Responsiveness for Academic Depth." In Curriculum Responsiveness. Case Studies in Higher Education, edited by H. Griesel, 81-101. Pretoria: SAUVCA.

Tuck, E., and K. W. Yang. 2012. "Decolonization is Not a Metaphor.” Decolonization: Indigeneity, Education and Society 1 (1): 1-40.

Vorster, J., and L. Quinn. 2012a. "Theorising the Pedagogy of a Formal Programme for University Lecturers.” In Re-Imagining Academic Staff Development: Spaces for Disruption, edited by L. Quinn, 51-70. Stellenbosch: Sun Media.

Vorster, J., and L. Quinn. 2012b. "Privileging Knowledge, Creating Knowers: An Analysis of a Formal Programme for University Lecturers." In Re-Imagining Academic Staff Development: Spaces for Disruption, edited by L. Quinn, 71-88. Stellenbosch: Sun Media.

Vorster, J., and L. Quinn. 2015. "Towards Shaping the Field: Theorising the Knowledge in a Formal Course for Academic Developers." Higher Education Research and Development 53 (5): 1031-44.

Republic of South Africa (RSA). 1997. The Higher Education Act. Pretoria: Government Printer.

Wheelahan, L. 2007. "How Competency-Based Training Locks the Working Class Out of Powerful Knowledge: A Modified Bernsteinian Analysis.” Journal of the Sociology of Education 28 (5): 637-51.

Young. M. 2008. Bringing Knowledge Back In: From Social Constructivism to Social Realism in the Sociology of Education. London: Routledge.

Zipin, L., A. Fataar, and M. Brennan. 2015. "Can Social Realism Do Social Justice? Debating the Warrants for Curriculum Knowledge Selection.” Education as Change 19 (2): 9-36. 